\title{
Material and Deterioration Characteristic Analysis for Inscribed Stones of Naksan Mountain Area of the Hanyangdoseong(Seoul City Wall), Korea
}

\author{
Myeong Seong Lee*, Yuri Kim, Myoungju Choie, Ji Hyun Yoo, Yu Bin Ahn \\ Conservation Science Division, National Research Institute of Cultural Heritage, Daejeon 34122, Korea
}

Received February 5, 2020

Revised February 10, 2020

Accepted February 17, 2020

*Corresponding author

E-mail: mslee75@korea.kr

Phone: $+82-42-860-9485$

Journal of Conservation Science 2020;36(1):060-072

https://doi.org/10.12654/JCS.2020.

36.1 .06

pISSN: 1225-5459, eISSN: 2287-9781

(c) The Korean Society of

Conservation Science for Cultural Heritage

This is an Open-Access article distributed under the terms of the Creative Commons Attribution Non-Commercial License (http://creativecommons.org/ licenses/by-nc/3.0) which permits unrestricted non-commercial use, distribution, and reproduction in any medium, provided the original work is properly cited.

\begin{abstract}
The Inscribed stones of Hanyangdoseong has been weathered for a long time because of external environment and living organisms. To establish a long-term conservation-management strategy for the inscription stones, the material characteristics of the inscription stones of Naksan Mountain Area were identified, and its deterioration state was diagnosed. Consequently, it was confirmed that the Inscription stones of Naksan Mountain Area mainly comprised coarse-to medium-grained pinkish granite and biotite granite, and, in part, comprised reddish granite, quartz porphyry, and aplite. Presently, the Inscription stones of Naksan Mountain Area, Hanyangdoseong, is undergoing a considerable decrease in physical properties because of physical, chemical, and biological weathering. Moreover, it has been confirmed that the type of damage, such as blistering, soiling, and dicolouration, on the surface shows a significantly high deterioration rate, and that conservation treatment might be required in future. In addition, because the possibility of damage recurrence is high even after the treatment, the conservation state must be regularly monitored.
\end{abstract}

Key Words Hanyangdoseong, Inscribed stones, Deterioration grade, Soiling, Conservation management

\section{INTRODUCTION}

Hanyangdoseong, the Seoul city wall(Historic site No. 10) was built around the time of the relocation of the capital of the Joseon dynasty(1392-1910) from Gaegyeong(present-day Gaeseong) to Hanyang(present-day Seoul). The wall, which was originally composed of earthen and stone sections, required approximately 120,000 man-days of labor until its completion in February 1396(the $5^{\text {th }}$ year of King Taejo's reign). In 1422(the $3^{\text {rd }}$ year of King Seojong's reign), the earthen sections were replaced with stone ones, while partial repairs were performed during the reigns of Kings Gwanghae and Gojong. The above-mentioned construction-related data can be found in various documents, and hundreds carvings on the wall also reveal information regarding the building of the Hanyangdoseong(Seoul Metropolitan Government, 2015).

The number of Inscribed stones was 288. In addition, the contents of the Inscribed stones comprise the following: section mark that indicates the built-up section, head of the county, officer, and workers. Therefore, they act as a significant source of evidence for proving the authenticity of world heritage. Although research on the Inscribed stones of Hanyangdoseong has been conducted many times, most of them have been conducted on the basis of its readings and forms(Oda, 1931; Min, 2008; Park, 2008; Seoul Metropolitan Government, 2009; 2015; Seoul Museum of History, 2012; Moon, 2014). However, the Inscribed stones of Hanyangdoseong has been weathered for a long time because 
of external environment and living organisms. In addition, because of the large area it is spread on, it is difficult to systematically investigate stone characteristics and perform conservation management.

The precise diagnosis of stone cultural heritages, such as the Inscribed stones of Naksan Mountain Area, requires considerable time and manpower, thereby presenting a practical limit to performing effective and continuous periodic monitoring. In this study, the first scientific investigation of the Inscribed stones of Naksan Mountain Area, including the deterioration assessment and deterioration type of 100 Inscribed stones there, was simplified, and the corresponding results were comprehensively analyzed. The deterioration characteristics were examined, and a conservation plan was suggested. These results will be used as basic data to establish the methodology of conservation-science research and establish long-term conservation-management plan.

\section{METHODS}

The materials and deterioration characteristics of the stones were analyzed to systematically investigate the Inscribed stones of Naksan Mountain Area. First, visual observation, magnetic susceptibility measurement, and mineralogy analysis were performed to understand the petrological characteristics of the Inscribed stones of Naksan Mountain Area. The visual observation briefly described the structure and particle size of the constituent rocks, and magnetic susceptibility was measured to confirm the homogeneity of the rocks. The magnetic-susceptibilitymeasuring instrument used was ZH Instruments(CZE)' SM30 model with the measurement limit of $10^{-5}$ SI units. The magnetic susceptibility intensity was expressed in $10^{-3} \mathrm{SI}$ units.

The samples, which dropped naturally because of weathering, were collected from the surroundings and subjected to mineralogical analysis. To investigate the semi-quantitative mineral composition and relative content of the constituent stones, thin sections were fabricated and observed under a polarizing microscope(LV100NPOL, Nikon, JPN). The X-ray diffraction analysis(Empyrean, Malvern Panalytical, NLD) was performed to precisely identify the relative frequency distribution of minerals, crystal structure and secondary minerals. The X-ray used as the target was $\mathrm{Cu} \mathrm{K} \alpha$, and the acceleration voltage of the anode and current of the filament were $40 \mathrm{kV}$ and $100 \mathrm{~mA}$, respectively.

To easily and quickly record the deterioration characteristics of the Inscribed stones of Naksan Mountain Area, Hanyangdoseong, a deterioration record table was prepared. For the record table, the basic survey items were determined by using both the general method for making a record of the deterioration of stone cultural heritages(The Korean Society of Conservation Science for Cultural Heritage, 2001) and the glossary of the types of stone-based cultural property deterioration published by ICOMOS (ICOMOS-ISCS, 2008). The main types of deterioration were first identified and, subsequently, the deterioration-type check items were set.

In addition, ultrasonic measurement(Pundit Lab, Proceq, CHE) and infrared thermography(ThermaCAM, SC660, FLIR, DEU) were performed to determine the physical deterioration of the rocks. Moreover, hyperspectral image analysis and environmental-impact assessment were performed to identify the biological damage state of the Inscribed stones of Naksan Mountain Area. Along with investigating the deterioration type, physical deterioration grade, discoloration, and biological deterioration grade were subdivided into 5 grades for the damage-level assessment; however, the total number of deterioration grades was curtailed to 3 for performing quick and easy judgment(Kim et al., 2013). Accordingly, an appropriate method for long-term conservation of the Inscribed stones of Naksan Mountain Area was suggested.

\section{CURRENT AND CONDITIONS}

Hanyangdoseong, which surrounded Seoul, was built as the capital city of the Joseon dynasty, and when the Joseon dynasty was established, it was moved from Gaekyeong to Hanyang. The city wall was renovated several times because it was built along the Baekak(Bukaksan Mountain), Nakta(Naksan Mountain), Mokkeok(Namsan Mountain), and Inwangsan Mountain. The city-wall castle has four main gates and four auxiliary gates. The four main gates are the Heunginjimun Gate in the east, Donuimun Gate in the west, Sungnyemun Gate in the south, and Sukjeongmun Gate in the north. The four auxiliary gates are the Honghwamun Gate 
in the northeast, Gwanghuimun Gate in the southeast, Changuimun Gate in the northwest, and Sodeokmun Gate in the southwest.

In 1422 (the $3^{\text {rd }}$ year of King Seojong's reign), the earthen sections were replaced with stone ones, while partial repairs were performed during the reigns of the Kings Gwanghae, Hyojong, Hyeonjong, Sukjong, Jeogjo, Sunjo, Heonjong, Choljong, and Gojong. However, during the Japanese colonial period, many city gates and walls were destroyed under the pretext of urban planning, and many were destroyed during the Korean War. Although Hanyangdoseong has been repaired several times, it is possible to distinguish the contraction time because of the different methods of building and the shape of the stones. Such contents can be found in literatures, such as Joseonwangjosillok(Annals of the Joseon dynasty), Seungjeongwomilgi(Diaries of the Royal Secretariat), and in the inscription on the wall.

A total of the 288 Inscribed stones include 46 in the inner part of the castle, 229 in the outer part of the castle, and 13 in the section where the rock and the wall except the wall collapsed(Table 1). The Inscribed stones of Hanyangdoseong is divided into Areas 1-15, starting from the top of the

Table 1. Status of the Inscribed stones of Hanyangdoseong by period(Seoul Metropolitan Government, 2015)

\begin{tabular}{ccccccccccccc}
\hline $\begin{array}{c}\text { Reign } \\
\text { (King) }\end{array}$ & Taejo & Sejong & Gwanghae & Hyojong & Sukjong & Jeongjo & Sunjo Heonjong & Cheoljong Gojong Unclear & Total \\
\hline Number & 29 & 118 & 1 & 1 & 23 & 2 & 38 & 4 & 2 & 1 & 69 & 288 \\
\hline $\begin{array}{c}\text { Share } \\
(\%)\end{array}$ & 10.1 & 41.0 & 0.3 & 0.3 & 8.0 & 0.7 & 13.2 & 1.4 & 0.7 & 0.3 & 24.0 & 100.0 \\
\hline
\end{tabular}
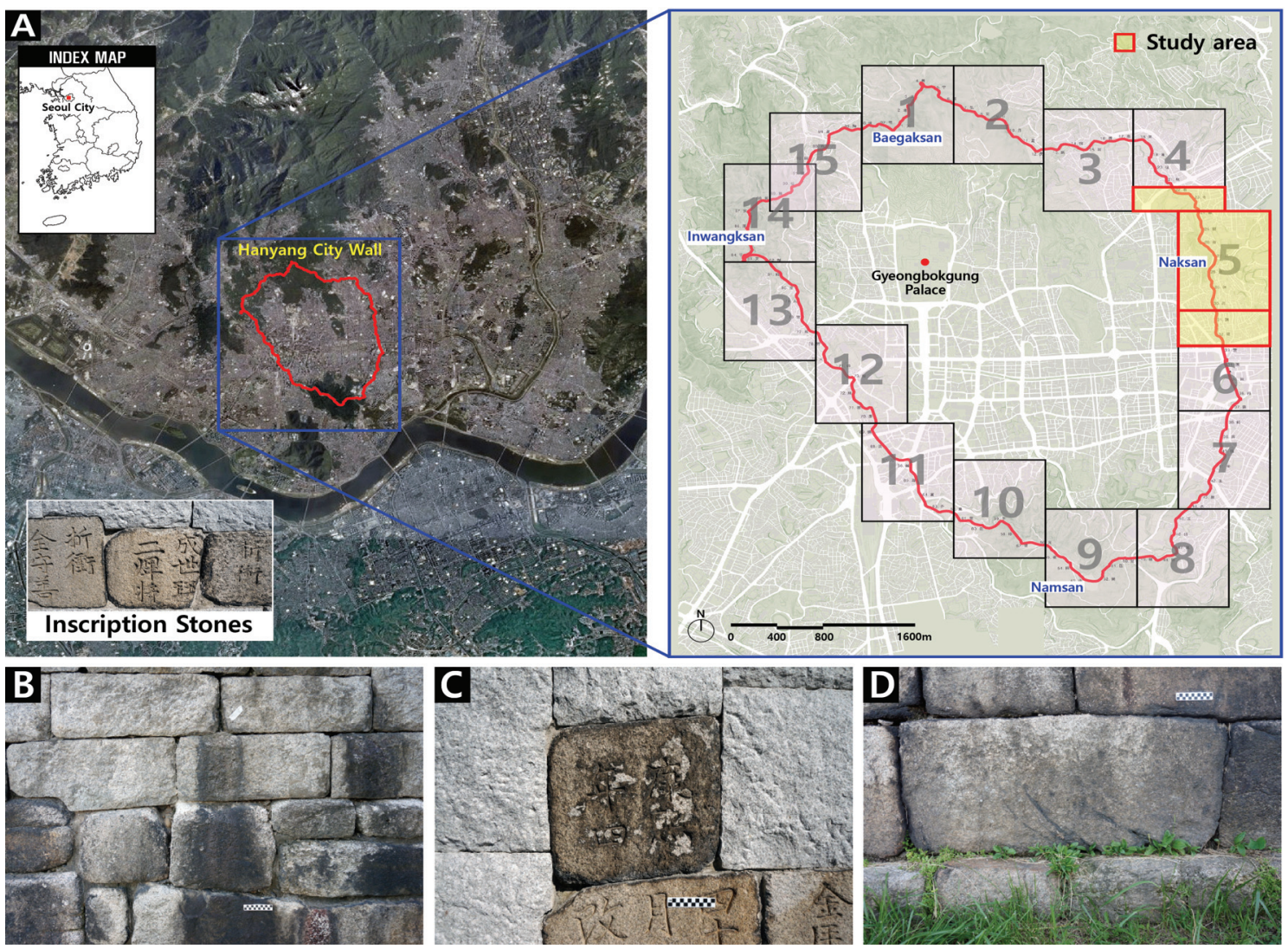

Figure 1. Current state of the Inscribed stones of Naksan Mountain Area, Hanyangdoseong; (A) Location and area status, (B) Soiling, (C) Blistering, (D) Plants. 
Table 2. Status of the Inscribed stones of Naksan Mountain Area

\begin{tabular}{ccccc}
\hline Reign (King) & Area 4 & Area 5 & Area 6 & Total \\
\hline Sejong & 6 & 41 & 9 & 56 \\
\hline Sukjong & - & 1 & 16 & 17 \\
\hline Unclear & 4 & 16 & 7 & 27 \\
\hline Total & 10 & 58 & 32 & 100 \\
\hline
\end{tabular}

Baekak Mountain, the base of the King-Taejo period of Hanyangdoseong(Figure 1A)(Seoul Metropolitan Government, 2015). A total of 100 Inscribed stones in the Naksan Mountain Area of this survey are all inscribed between the 1 st and 5th stages of the surface.

The periods of the Inscribed stones in Naksan Mountain Area were divided into the contents and the shape of the walls. The most frequent period is 56 Inscribed stones of the King-Sejong period, 27 of which are unclear and 17 of the King-Sukjong period. According to the zone, there are 10 Inscribed stones in Area 4, 58 in Area 5, and 32 in Area 6. Notably, the Inscribed stones of the King-Sejong period have the highest number in Area 5(Table 2). Presently, the Inscribed stones of Naksan Mountain Area, Hanyangdoseong, has undergone significant weathering because of external environment and organisms for a long time(Figure 1B 1D).

\section{MATERIAL CHARACTERISTICS}

\subsection{Petrographic characteristics and magnetic susceptibility}

The Inscribed stones of Naksan Mountain Area, Hanyangdoseong, mainly comprises coarse-to medium-grained pinkish granite and biotite granite, and partly comprises reddish granite, quartz porphyry, and aplite(Figure 2). The pinkish granite is difficult to identify the surface of the rock by dust, organisms, etc., but it mostly comprises coarse-to medium-grained quartz, alkali feldspar, plagioclase, and biotite. Notably, biotite granite is also significantly discolored, and dark color is pale brown to yellowish brown because of light gray or weathering(Figure 2A, 2B). Reddish granite has the same basic characteristics as that of pinkish granite, but the alkaline feldspar is more reddish and, therefore, visually distinguished(Figure $2 \mathrm{C}$ ). In some cases, yellowish of brown quartz porphyry and aplite are observed (Figure 2D, 2E).
The magnetic susceptibility measurements of the Inscribed stones of Naksan Mountain Area, Hanyangdoseong, showed that the considerable granularity of pinkish granite ranged from 1.34 to $7.79\left(\times 10^{-3}\right.$ SI units $)$ with the average value of 4.04(Figure 2G). The magnetic susceptibility of biotite granite and reddish granite was $0.06-6.61$, thereby indicating that the distribution of magnetite that controls the magnetic susceptibility value in granite is considerably heterogeneous. The characteristics of the magnetic-susceptibility distribution of the Inscribed stones of Naksan Mountain Area, Hanyangdoseong, have been reported to occur in granite mountains such as Namsan Mountain, Buaksan Mountain, Naksan Mountain, and Bukhansan Mountain around Seoul(Jo et al., 2012; Jo and Lee, 2015).

\subsection{Mineralogy characteristics}

To investigate the mineral composition, texture, and altered minerals due to the weathering of granite, polarized microscope analysis was performed on the specimens, and powder samples were prepared for performing X-ray diffraction analysis. Consequently, it was observed that the pinkish granite comprised coarse-to medium-grained quartz, microcline, plagioclase, biotite, and minor minerals such as muscovite, chlorite, and opaque minerals(Figure 3A). Most of quartz is morphology and microcracks are developed inside the particles and small crystal dolomite or shaped plagioclase is symbiotic and seritization. In addition, biotite is chlorinated along the boundary or cleavage of the particles, thereby indicating that the rocks are currently undergoing weathering(Figure 3B).

Biotite granite is well observed undulatory extinction and direct extinction of quartz and contains fine grains such as muscovite inside the particle, and the plagioclase shows a zonal structure(Figure 3C, 3D). Reddish granite was more orthoclase and microcline are perthite than pinkish granite, and biotite had mostly brown interference color(Figure 3E). 

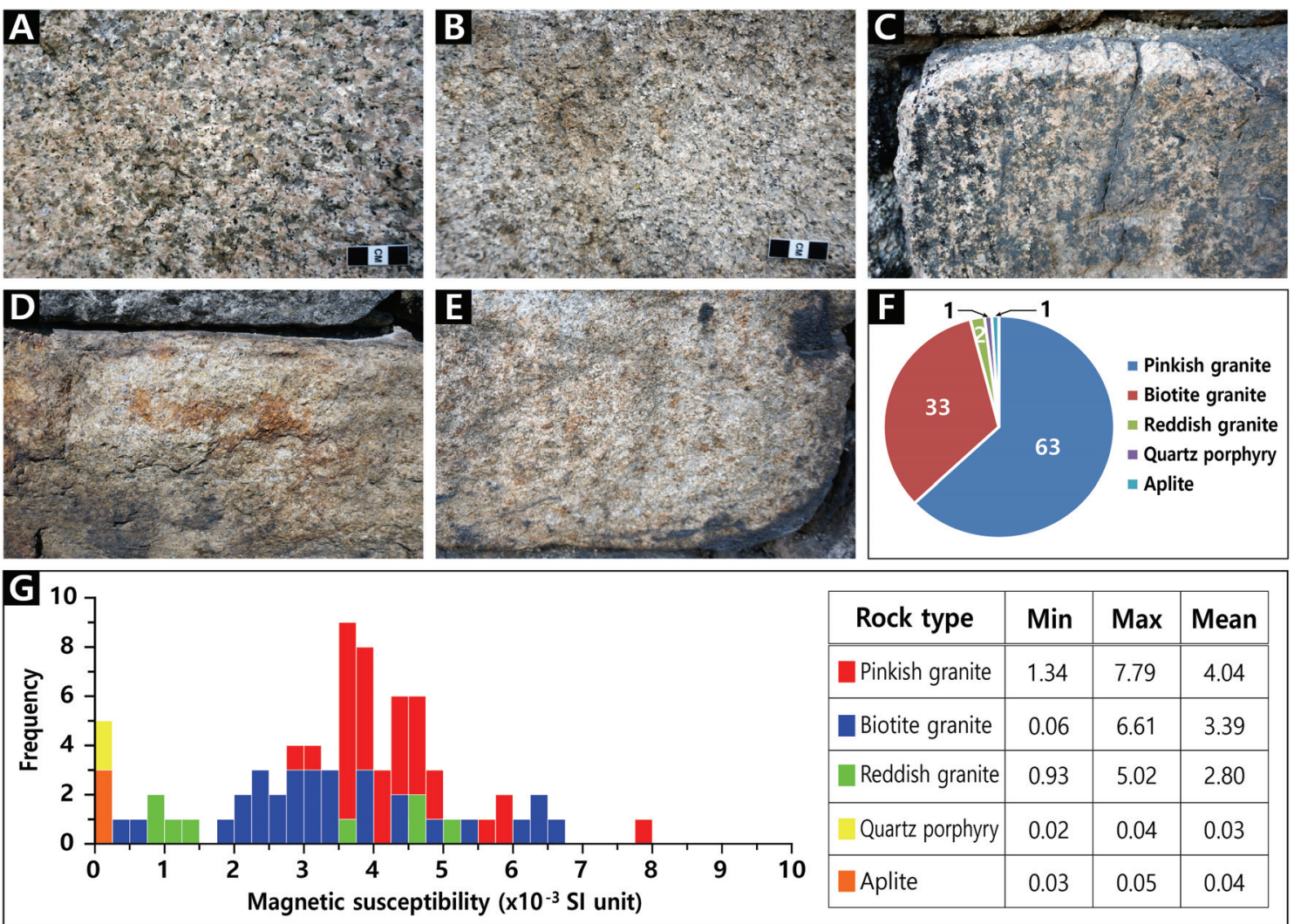

\begin{tabular}{|l|c|c|c|}
\hline Rock type & Min & Max & Mean \\
\hline a Pinkish granite & 1.34 & 7.79 & 4.04 \\
\hline Biotite granite & 0.06 & 6.61 & 3.39 \\
\hline Reddish granite & 0.93 & 5.02 & 2.80 \\
\hline Quartz porphyry & 0.02 & 0.04 & 0.03 \\
\hline Aplite & 0.03 & 0.05 & 0.04 \\
\hline
\end{tabular}

Figure 2. Lithological characteristics of the Inscribed stones of Naksan Mountain Area; (A) Pinkish granite, (B) Biotite granite, (C) Reddish granite, (D) Quartz porphyry, (E) Aplite, (F) Percentage of each rock type, (G) Magnetic susceptibility.
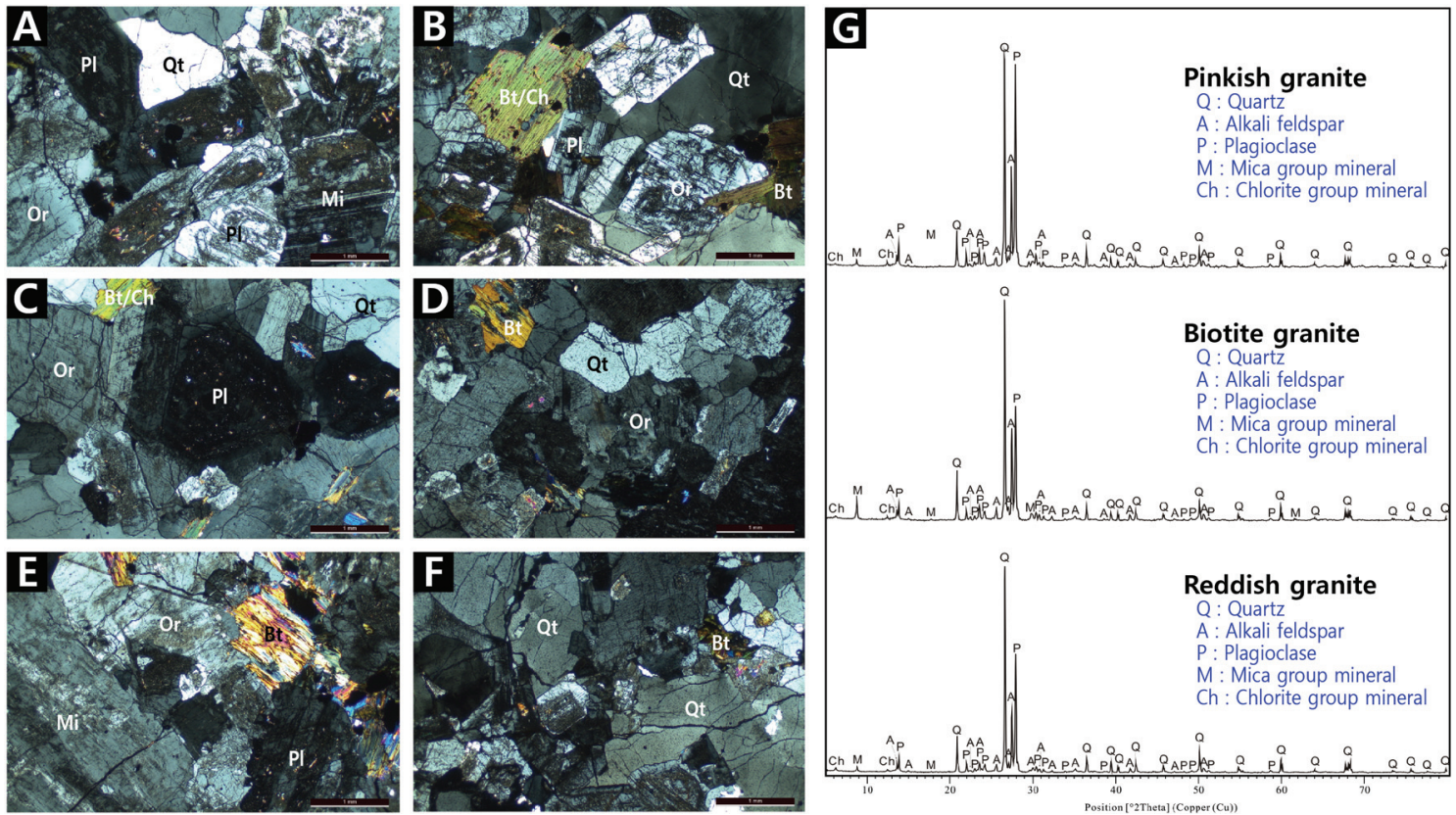

Figure 3. Mineralogical characteristics of the Inscribed stones of Naksan Mountain Area; (A, B) Pinkish granite, (C, D) Biotite granite, (E) Reddish granite, (F) Aplite, (G) X-ray diffraction analysis results. 
Aplite comprised fine-to medium-grained quartz, feldspar, and fine mica, and it had a granular structure(Figure 3F). The X-ray diffraction results revealed that quartz, alkali feldspar, plagioclase, and mica coarse minerals were commonly identified in all the samples. All the diffraction peaks that indicated the relative content among minerals showed similar composition trends; however, plagioclase was observed to be somewhat higher in pinkish granite(Figure 3G).

\section{DETERIORATION CHARACTERISTIC ANALYSIS}

\subsection{Deterioration status}

Prior to performing the efficient comprehensive survey of the Inscribed stones of Naksan Mountain Area, Hanyangdoseong, the deterioration types were classified and identified via the visual inspection of the area. To understand the overall conservation status of the Inscribed stones, a conservation- management survey report was prepared, and detailed check items were set by considering the deterioration type of the Inscribed stones of Naksan Mountain Area by using the general deterioration diagnosis record table of stone cultural heritages(The Korean Society of Conservation Science for Cultural Heritage, 2001).

The deterioration types that appear in the Inscribed stones
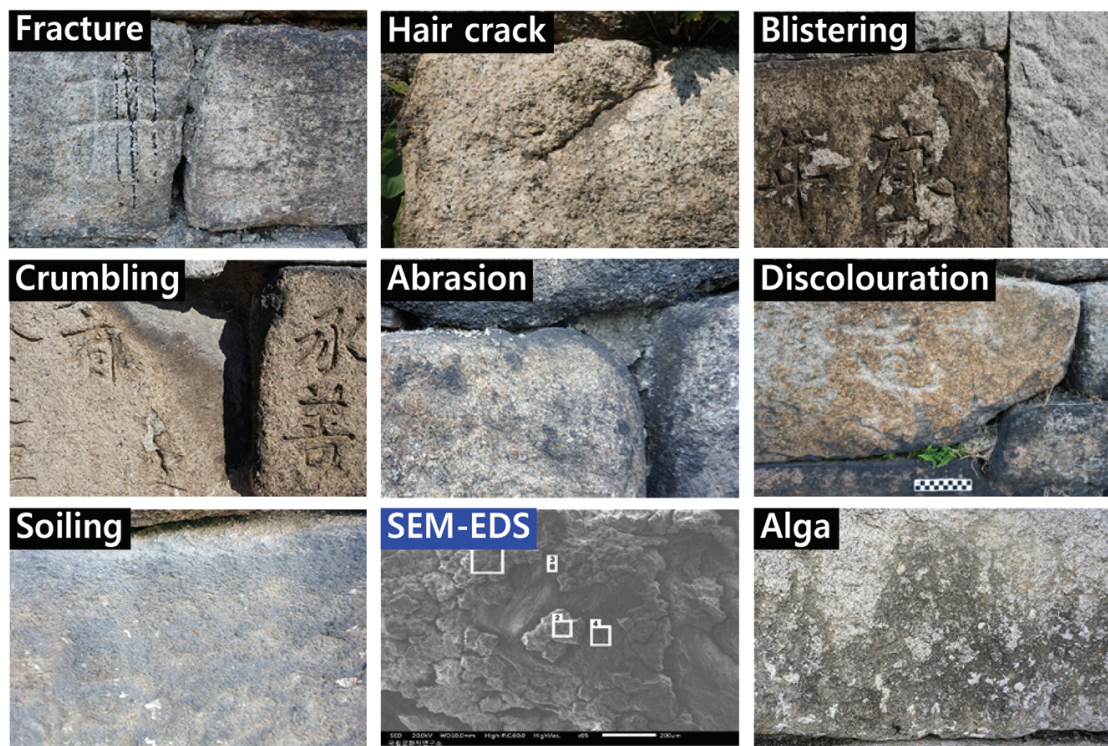
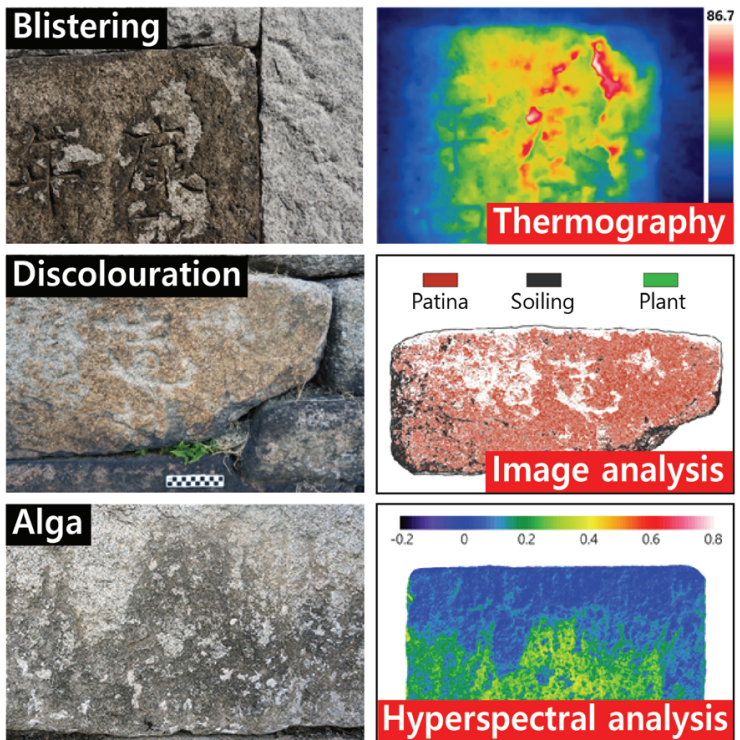

Figure 4. Deterioration status of the Inscribed stones of Naksan Mountain Area. 
Table 3. Criteria of deterioration degree for the Inscribed stones of Naksan Mountain Area

\begin{tabular}{|c|c|c|c|c|c|c|c|}
\hline Grade & Crack & Detachment & $\begin{array}{l}\text { Material } \\
\text { loss }\end{array}$ & $\begin{array}{l}\text { Discoloration } \\
\text { and deposit }\end{array}$ & $\begin{array}{l}\text { Biological } \\
\text { colonization }\end{array}$ & $\begin{array}{l}\text { Ultrasonic } \\
\text { velocity } \\
(\mathrm{m} / \mathrm{s})\end{array}$ & $\begin{array}{c}\text { Criteria } \\
(\text { Brown, 1981) }\end{array}$ \\
\hline 1 & Very weak & Very weak & Very weak & $0-20 \%$ & $0-20 \%$ & $>4,063$ & $\begin{array}{l}\text { No visible sign of rock-material } \\
\text { weathering }\end{array}$ \\
\hline 2 & Weak & Weak & Weak & $21-40 \%$ & $21-40 \%$ & $3,250-4,063$ & $\begin{array}{l}\text { Discoloration indicates the } \\
\text { weathering of rock material and } \\
\text { discontinuity surface }\end{array}$ \\
\hline 3 & Moderately & Moderately & Moderately & $41-60 \%$ & $41-60 \%$ & $2,438-3,250$ & $\begin{array}{l}\text { Less than half of the rock } \\
\text { material is decomposed and } \\
\text { disintegrated into soil }\end{array}$ \\
\hline 4 & Strong & Strong & Strong & $61-80 \%$ & $61-80 \%$ & $1,625-2,438$ & $\begin{array}{l}\text { More than half of the rock } \\
\text { material is decomposed and } \\
\text { disintegrated into soil }\end{array}$ \\
\hline 5 & Very strong & Very strong & Very strong & $81-100 \%$ & $81-100 \%$ & $<1,625$ & $\begin{array}{l}\text { All the rock material is } \\
\text { decomposed and disintegrated } \\
\text { into soil. The original mass } \\
\text { structure is still significantly } \\
\text { intact }\end{array}$ \\
\hline
\end{tabular}

stones of Naksan Mountain Area was crack, particularly, hair cracks, which showed a high frequency of occurrence. The highest frequency of the occurrence of discoloration and deposit types in the Inscribed stones of Naksan Mountain Area was attributed to dust soiling and coloration. In addition, biological contamination tends to be locally distributed, except for some Inscribed stones.

\subsection{Deterioration map}

On the basis of the above-mentioned damage conditions, a primary deterioration map was constructed during the outdoor survey. Subsequently, a corrected and supplemented secondary deterioration map was constructed by correcting and supplementing the primary map via reconfirmation and reading by using photo data in the laboratory. The deterioration map was prepared for the deterioration patterns induced by physical factors, and the chemical-and biological-deterioration rates were calculated using the hyperspectral image. Hyperspectral imaging is a spectroscopic method that is used to classify light into more than 200 bands at tens of nanometers. Clustering and classifying the spectral characteristics of each damaged image in the image obtained from the measurement yields the number of pixels in the damaged region(Chun et al., 2015).

The deterioration types that appear in the Inscribed stones of Naksan Mountain Area include fracture, hair cracks, blistering, crumbling, chipping, and roughening(Figure 5A). Most cracks were hair cracks, which were 431 in total. The most frequent cracks were found in Area 5. Particularly, there are 10 stones in which 10 or more hair cracks occurred, and in some stones hair cracks up to 19 were observed.

Blistering and crumbling occurred in the absence of 81 and 85 , in addition, it is confirmed in the absence of chipping 16 and roughening 11. Among these, 16 had more than $10 \%$ occurrences of expansion and detachment compared with the member area, and 4 had more than $20 \%$. Crumbling mostly appeared at the corners and occurred in less than $20 \%$ cases, except for some parts. Chipping occurred in less than $10 \%$ in all but Area 5, and unevenness showed more than 50\% damage in some parts of Area 5(Figure 5C).

As a result of hyperspectral image analysis(Figure 5B), the major damage in the Inscribed stones of Naksan Mountain Area occurred in the Inscribed stones of 56 and 97 because of dust soiling and coloration. Particularly, soiling occurred in all areas except Area 4. The deterioration rate of soiling was $50 \%$, and the most frequent occurrence is absent, but Inscribed stones, which has occurred more than $80 \%$, has 14 and needs proper conservation management. In the case of coloration, both the number of occurrences(56) and deterioration rate were lower than those in the case of soiling; however, the incidence rate was more than $80 \%$ for 4 Inscribed stones in Area 6.

Among all the areas, the deterioration rate due to soiling 
was the most significant for Area 5. The coloration was observed to be most significant in Area 6. However, the biological damage of the Inscribed stones was considerably low in most areas except for Areas 4 and 5, and it is confirmed that the damage occurred mainly in Area 4. In summary, soiling and coloration are the most significant

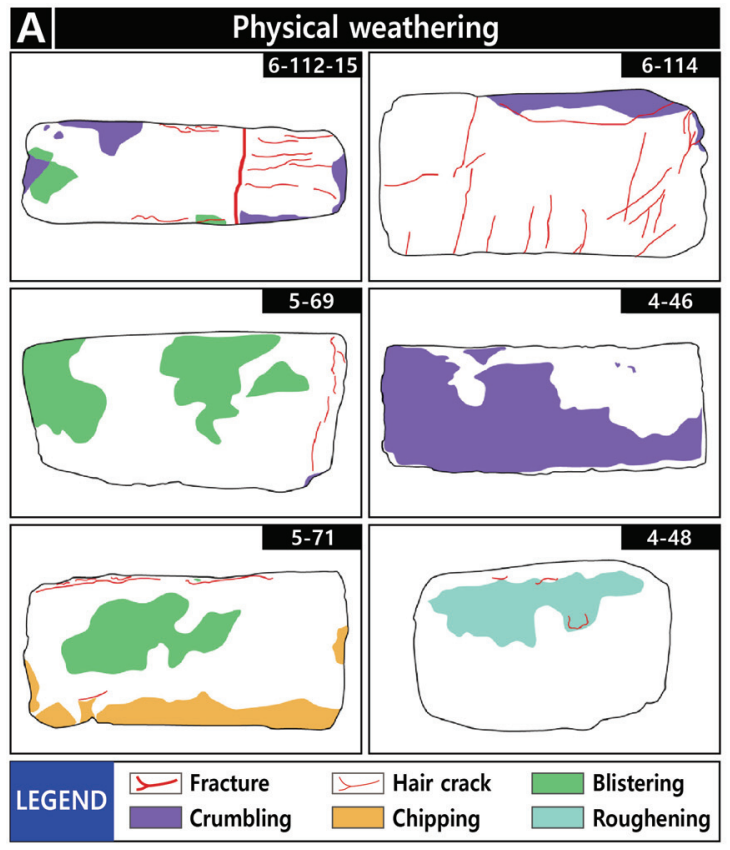

\section{B Chemical \& Biological weathering}

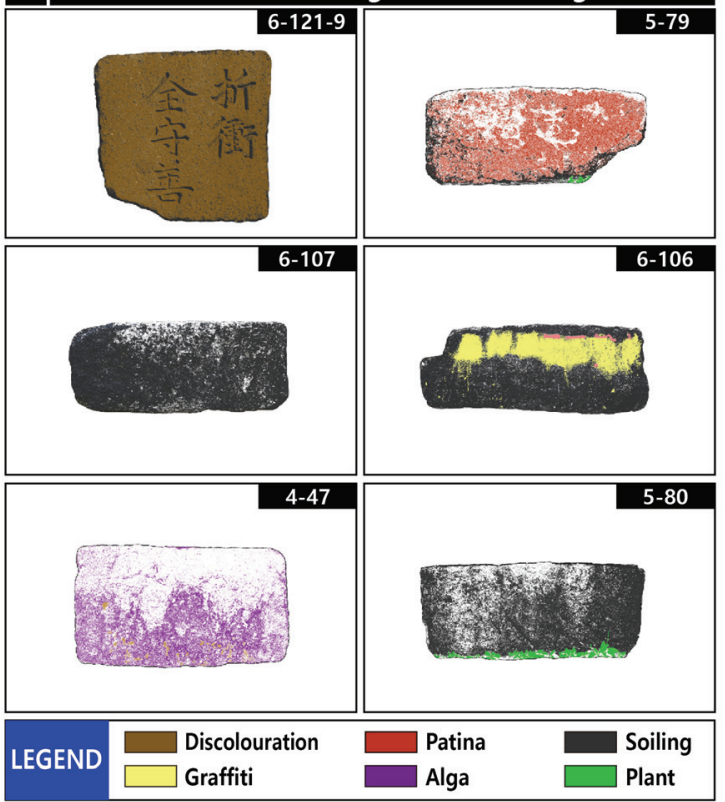

deterioration types in the Inscribed stones of Naksan Mountain Area. However, in part, the issues associated with blistering and crumbling also require long-term conservation management.
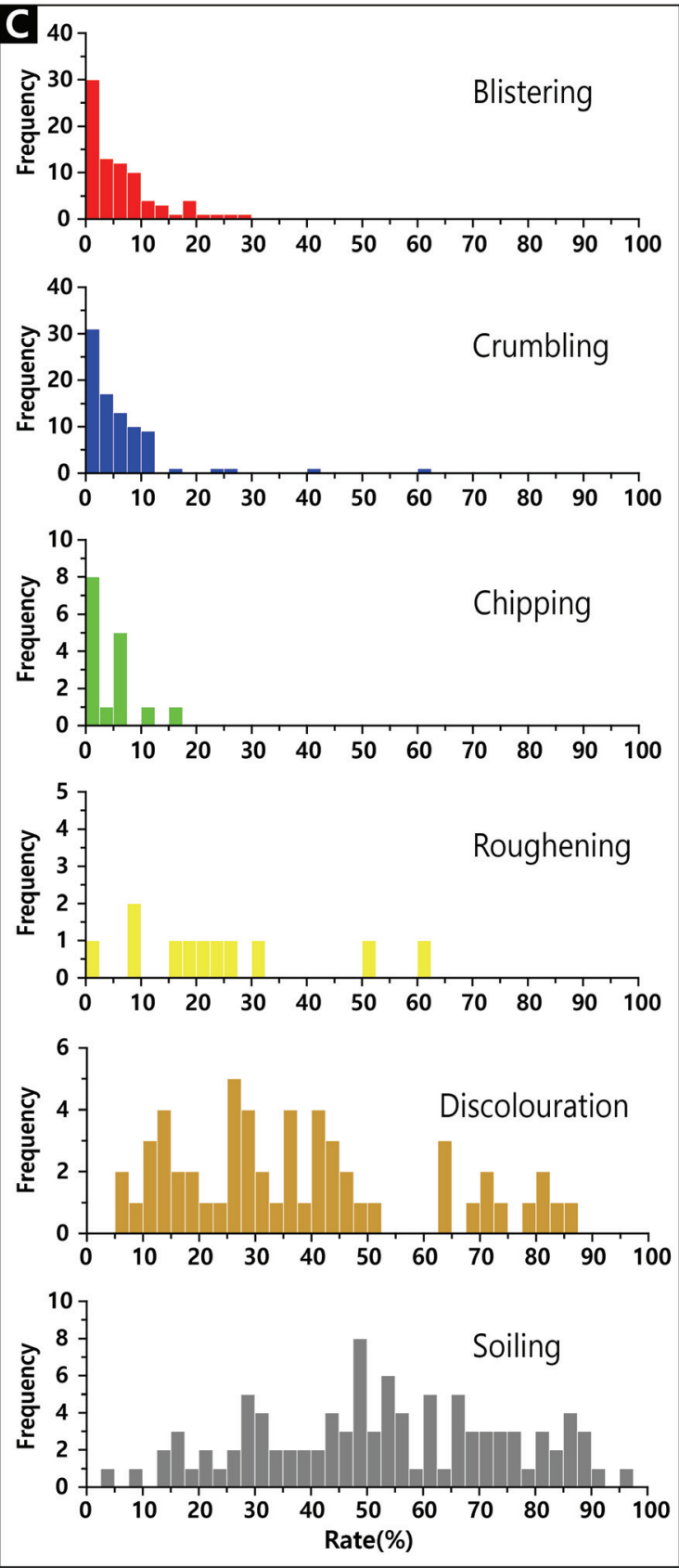

Figure 5. Deterioration maps and rates of the Inscribed stones of Naksan Mountain Area; (A) Physical deterioration maps, (B) Chemical and biological deterioration maps, (C) Deterioration rates. 


\subsection{Ultrasonic measurements}

Various methods exist for quantitatively measuring the physical properties of rocks. The methods include uniaxial compressive strength measurement, specific gravity and porosity measurement, and rebound hardness measurement. However, if the test subject is a cultural heritage, a non-destructive method must be used. Ultrasonic measurement has been widely used for evaluating the properties of stone cultural heritages by using non-destructive methods, as it has excellent on-site portability and stability, and it leaves no trace after performing measurement. To calculate the material-weathering grade, there exists a method that is based on the ultrasonic velocity of fresh rocks. The stone of Hanyangdoseong is the Seoul granite from Namsan
Mountain, Inwangsan Mountain, Buaksan Mountain, Naksan Mountain, among others(Jo and Lee, 2015). Because quarrying is difficult in the aforementioned areas, the weathering grades are calculated on the basis of the ultrasonic velocity measured on the fresh stones of Yangju granite near Seoul(National Research Institute of Cultural Heritage, 2012).

By calculating the weathering grade for 100 Inscribed stones in the survey, it was confirmed that Grade 1 was $1 \%$, Grade 2 11\%, Grade 3 31\%, Grade 4 53\%, and Grade 5 $4 \%$ (Table 4). Analyzing the share of weathering grades according to the types of rocks that constitute the Inscribed stones, pinkish granite has $59 \%$ of Grade $4,38 \%$ of Grade 3, $8 \%$ of Grade 2, 3\% of Grade 5, and $2 \%$ of Grade 1 . In addition, quartz porphyry had $100 \%$ of Grade 2; aplite had

Table 4. Coefficient of weathering, and weathering grade according to ultrasonic velocity

\begin{tabular}{cccccc}
\hline & Weathering grade & $\begin{array}{c}\text { Coefficient of } \\
\text { weathering }(\mathrm{k})\end{array}$ & $\begin{array}{c}\text { Ultrasonic } \\
\text { velocity }(\mathrm{m} / \mathrm{s})\end{array}$ & Number & Rate(\%) \\
\hline Grade 1 & Fresh & $>0.0$ & $>4,063$ & 1 & 1 \\
\hline Grade 2 & Slightly weathered & $0.0-0.2$ & $3,250-4,063$ & 11 & 11 \\
\hline Grade 3 & Moderately weathered & $0.2-0.4$ & $2,438-3,250$ & 31 & 31 \\
\hline Grade 4 & Highly weathered & $0.4-0.6$ & $1,625-2,438$ & 53 & 53 \\
\hline Grade 5 & Completely weathered & $0.6-1.0$ & $<1,625$ & 4 & 4 \\
\hline
\end{tabular}

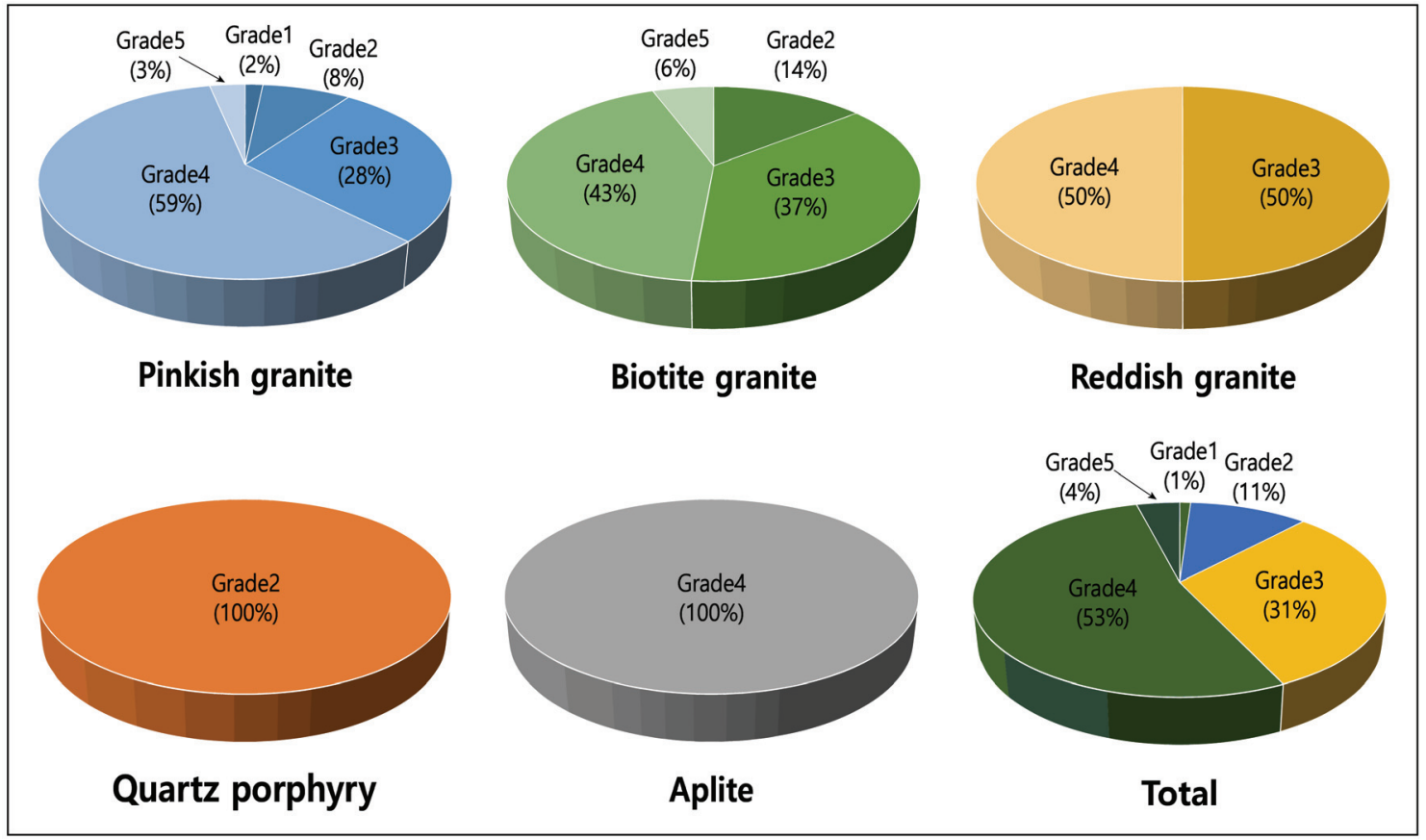

Figure 6. Share of the weathering grade according to rock type of the Inscribed stones of Naksan Mountain Area. 
$100 \%$ of Grade 4; reddish granite had $50 \%$ each of Grades 3 and 4; biotite granite had $43 \%$ of Grade 4, 37\% Grade 3, 14\% Grade 2, and 6\% Grade 5(Figure 6). Notably, long-term conservation management seems to require intensive conservation management for the stones of Grades 4 and 5 .

\subsection{Deterioration Assessment}

In the Inscribed stones of Naksan Mountain Area, Hanyangdoseong, various deterioration types occurred in combination. Therefore, to establish a long-term conservation plan for each inscribed stone, the damages of the stones, as well as the result of classification and frequency of the occurrence of damages, must be identified. To quantitatively identify the physical, chemical, and biological damages identified in each stone, the damages were classified into 5 stages. In addition, for performing the efficient management of the Inscribed stones of Naksan Mountain Area, a comprehensive management grade of 3 was assigned to determine the urgent need for the conservation management for all stones(Table 5).

Analyzing the share of Inscribed stones that resulted in detailed deterioration types, it is confirmed that hair $\operatorname{cracks}(87 \%)$ for crack and deformation, crushing $(91 \%)$ for detachment, abrasion(98\%) for material loss, soiling(97\%) for discoloration and deposit, and plants(34\%) received the largest share of biological contamination. In addition, the highest incidence of deterioration type was abrasion(98\%), followed by soiling(97\%), crumbling(91\%), hair cracks and blistering(87\%), and discoloration(56\%). Accordingly, it is interpreted that these are major damages to the Inscribed stones.
After calculating the grade occupancy rate of the deterioration type of the Inscribed stones, it was confirmed that crack and deformation were $11 \%$ in Grade $1,64 \%$ in Grade 2, 24\% in Grade 3, 1\% in Grade 4, and $0 \%$ in Grade 5. Detachment was calculated as $0 \%$ in Grade $1,43 \%$ in Grade 2, 50\% in Grade 3, 5\% in Grade 4, and 2\% in Grade 5. Material loss was calculated as $2 \%$ in Grade $1,80 \%$ in Grade 2, 18\% in Grade 3, and $0 \%$ in both Grades 4 and 5 . Discoloration and deposit were calculated as 3\% in Grade 1, $8 \%$ in Grade 2, 15\% in Grade 3, 27\% in Grade 4, and 47\% in Grade 5. Last, biological contamination was calculated as $96 \%$ in Grade 1, 2\% in Grade 2, 1\% in both Grades 3 and 4 , and $0 \%$ in Grade 5. The proportion of Grade 5, which indicates the most considerable deterioration status, was highest in the deterioration type of discoloration and deposit; however, detachment was the most obvious among physical-deterioration types(Figure 7).

In addition, as a result of examining the deterioration degree by the area where the Inscribed stones of Naksan Mountain Area is located, the regions with the highest share of Grades 4 and 5, both of which are two of the most significant deterioration grades, were observed in Area 6 as crack and deformation, Area 4 as detachment, and material loss does not difference. Discoloration and deposit were observed in Area 6 and biological contamination in Area 4 (Table 6). According to the distribution patterns of deterioration grades by area, Area 4 is relatively better than Areas 5 and 6; however, the difference is not significant.

The results showed that the major damages occurring in the Inscribed stones of Naksan Mountain Area Hanyangdoseong, ranged from the most frequent physical damages to detachment, material loss, and crack and

Table 5. Criteria of comprehensive degree for the Inscribed stones of Naksan Mountain Area

\begin{tabular}{|c|c|c|}
\hline & Grade & Criteria \\
\hline 1 & Maintain & $\begin{array}{l}\text { None or slight deterioration. Single physical-deterioration form observed. Conservation } \\
\text { intervention is not urgently considered. None or slight discoloration due to organic and } \\
\text { inorganic contaminants. Surface coverage of contaminants is less than } 20 \% \text {. }\end{array}$ \\
\hline 2 & Monitoring & $\begin{array}{l}\text { Moderate deterioration. Multiple deteriorations interacted; for example, a set of crack and } \\
\text { break-out, or crack and exfoliation. Although conservation intervention is not urgent, } \\
\text { short-term monitoring is required. Moderate discoloration due to organic and inorganic } \\
\text { contaminants. Surface coverage of contaminants between } 20 \text { and } 50 \% \text {. }\end{array}$ \\
\hline 3 & $\begin{array}{c}\text { Conservation } \\
\text { treatment }\end{array}$ & $\begin{array}{l}\text { Intensive deterioration. Multiple deterioration observed, resulting in material disintegration } \\
\text { in short period. Conservation intervention is urgently needed. Intensive discoloration due } \\
\text { to organic and inorganic contaminants. Surface coverage more than } 50 \% \text {. }\end{array}$ \\
\hline
\end{tabular}




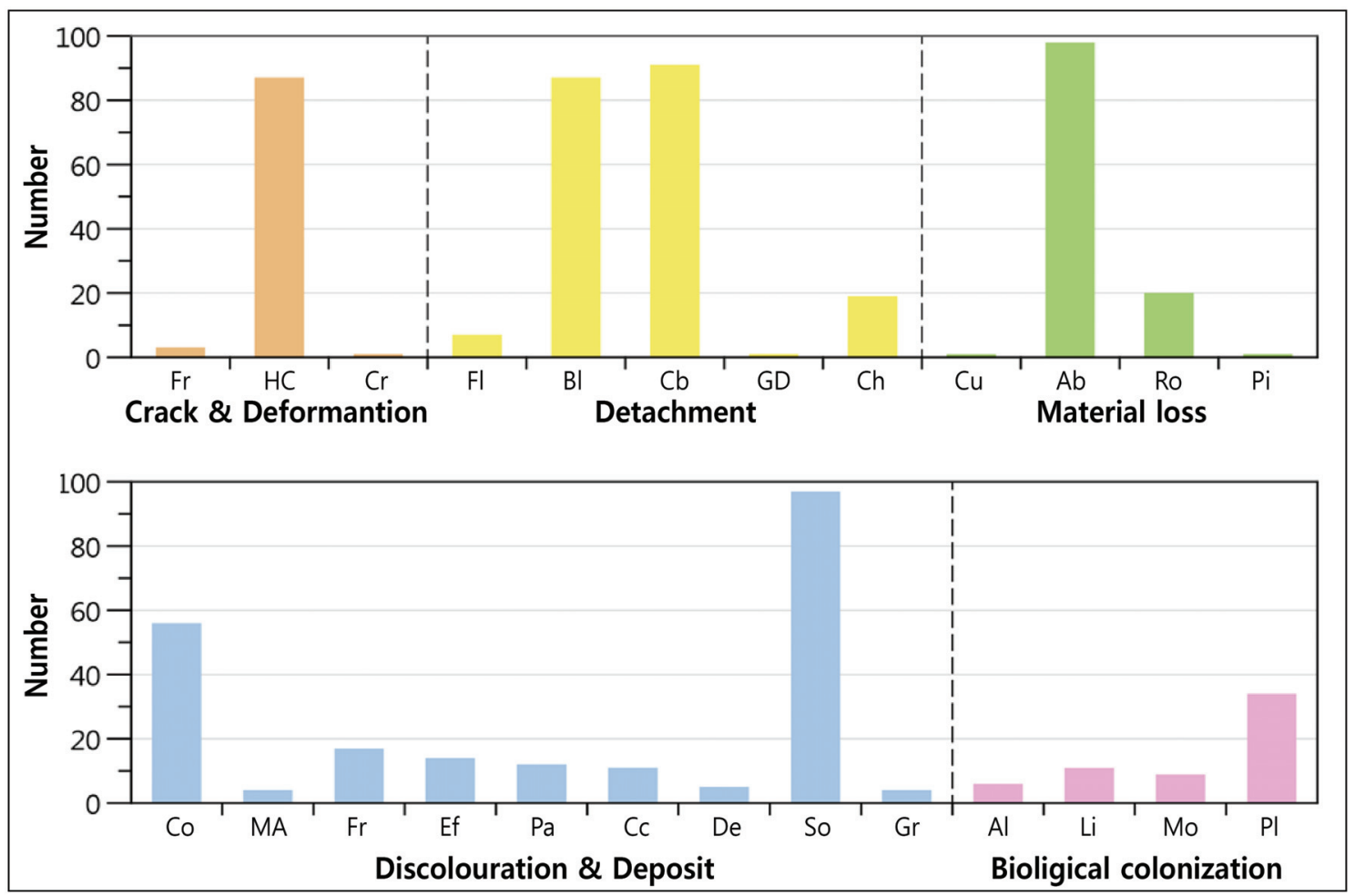

Figure 7. Comparison of the number of stones by deterioration types in the Inscribed stones of Naksan Mountain Area.

Table 6. Deterioration grades by weathering forms and areas of the Inscribed stones of Naksan Mountain Area

\begin{tabular}{|c|c|c|c|c|c|c|c|}
\hline Weathering forms & Area & Grade 1 & Grade 2 & Grade 3 & Grade 4 & Grade 5 & Total \\
\hline \multirow{4}{*}{$\begin{array}{l}\text { Crack and } \\
\text { deformation }\end{array}$} & 4 & 0 & 8 & 2 & 0 & 0 & 10 \\
\hline & 5 & 7 & 35 & 16 & 0 & 0 & 58 \\
\hline & 6 & 4 & 21 & 6 & 1 & 0 & 32 \\
\hline & Total & 11 & 64 & 24 & 1 & 0 & 100 \\
\hline \multirow{4}{*}{ Detachment } & 4 & 0 & 6 & 3 & 1 & 0 & 10 \\
\hline & 5 & 0 & 29 & 26 & 2 & 1 & 58 \\
\hline & 6 & 0 & 8 & 21 & 2 & 1 & 32 \\
\hline & Total & 0 & 43 & 50 & 5 & 2 & 100 \\
\hline \multirow{4}{*}{ Material loss } & 4 & 2 & 7 & 1 & 0 & 0 & 10 \\
\hline & 5 & 0 & 44 & 14 & 0 & 0 & 58 \\
\hline & 6 & 0 & 29 & 3 & 0 & 0 & 32 \\
\hline & Total & 2 & 80 & 18 & 0 & 0 & 100 \\
\hline \multirow{4}{*}{$\begin{array}{c}\text { Discoloration } \\
\text { and deposit }\end{array}$} & 4 & 3 & 2 & 2 & 3 & 0 & 10 \\
\hline & 5 & 0 & 4 & 12 & 19 & 23 & 58 \\
\hline & 6 & 0 & 2 & 1 & 5 & 24 & 32 \\
\hline & Total & 3 & 8 & 15 & 27 & 47 & 100 \\
\hline \multirow{4}{*}{$\begin{array}{l}\text { Biological } \\
\text { contamination }\end{array}$} & 4 & 7 & 1 & 1 & 1 & 0 & 10 \\
\hline & 5 & 57 & 1 & 0 & 0 & 0 & 58 \\
\hline & 6 & 32 & 0 & 0 & 0 & 0 & 32 \\
\hline & Total & 96 & 2 & 1 & 1 & 0 & 100 \\
\hline
\end{tabular}


Table 7. Comprehensive management grade for each zone of the Inscribed stones of Naksan Mountain Area

\begin{tabular}{cccccc}
\hline & Grade & Area 4 & Area 5 & Area 6 & Total \\
\hline 1 & Maintain & - & - & - & - \\
\hline 2 & Monitoring & 8 & 19 & 11 & 38 \\
\hline 3 & $\begin{array}{c}\text { Conservation } \\
\text { treatment }\end{array}$ & 2 & 39 & 21 & 62 \\
\hline & Total & 10 & 58 & 32 & 100 \\
\hline
\end{tabular}

deformation. Notably, discoloration and deposit comprised significant soiling and coloration. In addition, after calculating the deterioration of the Inscribed stones of Naksan Mountain Area, Hanyangdoseong, as a comprehensive management grade, there was no regular management member with Grade 1. The emphasis management member at grade 2 is 38 , and the intensity management member at grade 3 is 62 (Table 7).

\section{DISCUSSION AND CONCLUSION}

It is confirmed that the physical properties of the Inscribed stones of Naksan Mountain Area are significantly reduced because of physical-, chemical-, and biological-damage factors, as the stones have been outdoors for hundreds of years and weathered because of physical, chemical, biological, and structural factors. The deteriorationassessment results showed that a significant number of the Inscribed stones exhibited surface damage and low physical properties. After analyzing the meteorological environment of Seoul for the past 30 years(1981-2010) in the region where Hanyangdoseong is located, the average temperature in winter was below freezing, the average number of snowing days approximately 25 days, and the average number of frost days was approximately 66 days. The Inscribed stones of Naksan Mountain Area were damaged because of the pressure generated by the freezing-thawing of incoming water in the form of snow and frost.

In addition, soiling(black) observed in most Inscribed stones is attributed to black pollutants, i.e., dust and carbon, generated because of the industrialization since the 1960s. In the Inscribed stones, the rock-color change occurred because of $\mathrm{Fe}$ being eluted via chemical reaction with water and deposited on the surface, thereby resulting in discoloration. The repair records of Hanyangdoseong show that ash was used several times as a repair material. Accordingly, the surface of the Inscribed stones might have damaged because of both the pressure generated during the elution of the ash and the recrystallization of salt.

Although biological contamination is relatively good, algae, lichens, and moss can weather rocks via biochemical action. In addition, some of the members of the Inscribed stones are hard to withstand the upper parts because of the rock-strength weakening due to hair cracks, scaling, crumbling, and surface contaminants. Especially, some members have previously been soiled to the extent that only the hand is broken, thereby making it difficult to perform any conservation treatment.

On the basis of the results of this study, the deterioration types, such as blistering, soiling, and coloration on the surface of the Inscribed stones of Naksan Mountain Area, have been shown to be significantly intense and, accordingly, conservation treatment is required in future. In addition, there exists a high possibility of damage reoccurrence even after treatment, thereby necessitating the regular monitoring of the conservation status.

\section{ACKNOWLEDGMENTS}

This study was funded by the Cultural Heritage R\&D Project of the National Research Institute of Cultural Heritage, Cultural Heritage Administration, and we are deeply grateful for their administrative and financial support.

\section{REFERENCES}

Brown E.T., 1981, Rock characterization testing and monitoring: ISRM suggested methods. Pergamon Press.

Chun, Y.G., Lee, M.S., Kim, Y.R., Lee, M.H., Choi, M.J. and Choi, K.H., 2015, Utilization of hyperspectral image analysis for monitoring of stone cultural heritage. Jounal 
of Conservation Science, 31, 395-402. (in Korean with English abstract)

ICOMOS-ISCS, 2008, Illustrated glossary on stone deterioration patterns. ICOMOS, 1-86.

Jo, Y.H. and Lee, C.H., 2015, Analysis of ancient document and establishment of petrological database for presumption of stone source area of the Seoul city wall, Korea. Journal of the Petrological Society of Korea, 24(3), 193-207. (in Korean with English abstract)

Jo, Y.H., Lee, C.H., Yoo, J.H., Kang, M.K. and Kim, D.M., 2012, Petrological classification and provenance interpretation of the Sungnyemun stone block foundation, Korea. MUNHWAJAE Korean Journal of Cultural Heritage Studies, 45(3), 174-193. (in Korean with English abstract)

Kim, J., Jo, Y.H. and Lee, C.H., 2013, Material and deterioration characteristic analysis for stone sculptures in Gyeongbokgung royal palace, Seoul. Journal of Conservation Science, 29(4), 407-420. (in Korean with English abstract)

Min, D.S., 2008, Inscriptions engraved on the stones of Seoul city wall with information on its construction. Hyangto Seoul, 71, 208-253. (in Korean)
Moon, I.S., 2014, A study on the inscription stones of Seoul city wall. The Journal of Seoul Studies, 55, 1-109. (in Korean with English abstract)

National Research Institute of Cultural Heritage, 2012, Nondestructive evaluation of weathering degree for stone cultural heritage using ultrasonic test. 1-20. (in Korean)

Oda, S., 1931, About the origin of relocation of Gyeongseong (the capital) and its fortress wall. Joseon, 197, 46-47. (in Japan)

Park, G.H., 2008, The forgotten inscribed stones of Seoul city wall. Joeun Publishing(Seoul). (in Korean)

Seoul Metropolitan Government, 2009, Basic plan-1 for the maintenance of Seoul city wall. 76-83. (in Korean)

Seoul Metropolitan Government, 2015, Hanyangdoseong, the Seoul city wall: Inscribed stones and construction records. 1-225. (in Korean with English)

Seoul Museum of History, 2012, Record of the excavation of Seoul city wall $\mathbb{I}$ : Results of the survey of the inscribed stones of Seoul city wall. 128-131. (in Korean)

The Korean Society of Conservation Science for Cultural Heritage, 2001, Research on conservation and management of stone cultural heritage. Cultural Heritage Adminstration, 1-1068. (in Korean) 